\title{
STANDARDIZATION OF POTASSIUM PERMANGANATE SOLUTION BY SODIUM OXALATE
}

\author{
By R. S. McBride
}

CONTENTS

I. IN

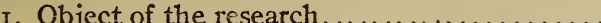

2. Considerations affecting the choice of a standard............ $6 \mathrm{I}_{2}$

3. Reasons for the choice of sodium oxalate............... $6 \mathrm{I}_{3}$

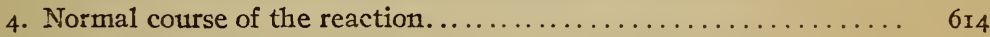

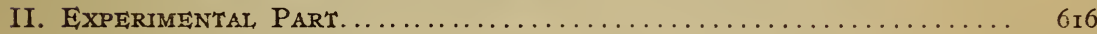

I. Reagents employed........................... 616

2. Weighing of oxalate and permanganate used............ 6 I 7

3. Effect of conditions upon the result of a titration ............ 6 I8

(a) End-point corrections..................... 6I9

(b) Rate of addition of the permanganate ............... $62 \mathrm{I}$

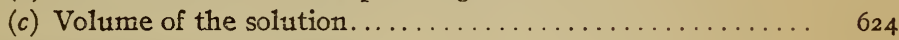

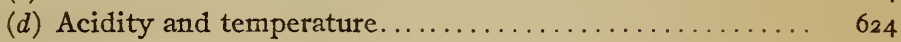

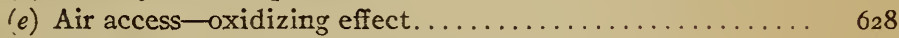

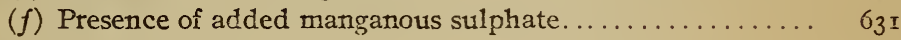

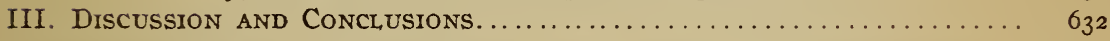

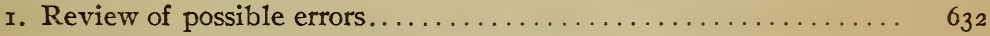

(a) Loss of oxalic acid by volatilization............... 633

(b) Decomposition of exalic acid by water............. $6_{33}$

(c) Decomposition of oxalic acid by sulphuric acid,....... 633

(d) Oxidation of oxalic acid by the air.................... 634

(e) Incomplete oxidation of the oxalic acid........... 636

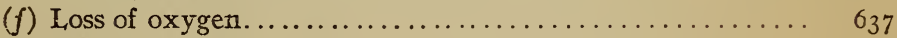

(g) Incomplete reduction of the permanganate.......... 639

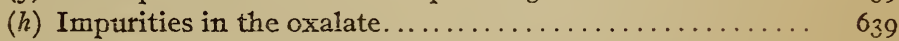

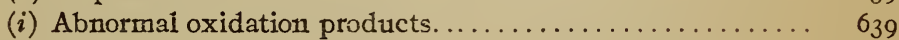

2. Summary and conclusions.......................... 640

3. Method recommended for use........................ $64 \mathrm{I}$

4. Accuracy and precision attainable.................... $64 \mathrm{I}$ 


\section{INTRODUCTORY PART}

\section{OBJECT OF THE RESEARCH}

The standardization of potassium permanganate solutions has been the subject of much study and an excessive amount of controversy. There have been far too many standards proposed for this work to permit one not familiar with the subject to select the best; and, in fact, it is doubtful whether or not any one of those standards proposed can in all senses be considered the best. However, the work of the Bureau of Standards has demanded that some substance be selected for this use which could be employed with a certainty of a reasonably correct result. It was desired, if possible, that the standard selected should serve a threefold purpose, viz: First, as a primary standard of oxidimetry; second, as a working standard for regular use in our own laboratories; and third, as a substance which could be distributed by the Bureau with a guarantee both as to its purity and as to its reducing value when used under specified conditions.

Although the voluminous literature relating to the standardization of potassium permanganate solutions has been examined with considerable care, it is not thought desirable to give a history of the subject, or even a bibliography. None of the theories considered here are new; but it is hoped that the experimental facts presented will be of value as a guide to the proper use of sodium oxalate as a standard.

\section{CONSIDERATIOINS AFFECTING THE CHOICE OF A STANDARD}

It is seldom that a single measure can be used both as a primary reference standard and as a regular working standard, but for some volumetric work this is possible. A substance to serve any such double function must be such that the following conditions will be fulfilled:

(a) Reasonable ease of preparation and accurate reproducibility of material must be assured.

(b) The purity must be determinable with sufficient accuracy, and the purified material must be stable under ordinary conditions of the laboratory. 
(c) The use of the material in regular work must demand neither complex apparatus nor difficult manipulations.

(d) Such precision must be obtainable when it is used with ordinary care that one, or at the most a very few determinations suffice for the fixing of the value of a standard solution.

(e) The accuracy obtained under ordinary conditions of its use in standardization must be at least as great as that required in the use of the solution to be standardized.

\section{REASONS FOR THE CHOICE OF SODIUM OXALATE}

In the above six respects it appeared that sodium oxalate was probably best suited to our needs, and a detailed study of this standard was undertaken.

The methods of preparation and testing of sodium oxalate have been carefully studied by Sörensen. ${ }^{1}$ In continuation of such study, Mr. J. B. Tuttle and Dr. William Blum, of this laboratory, have carried out several important lines of work and, at the request of the Bureau of Standards, several firms of manufacturing chemists have improved their methods of preparation of sodium oxalate on a large scale. At this point it is sufficient to state that all of this work indicates that it can be prepared in a suitable form at reasonable expense; that it is reproducible; that its purity can be tested readily; and that once purified it is satisfactorily stable under ordinary conditions. ${ }^{2}$

The discussion of the other three criteria as to the value of sodium oxalate, viz, convenience, precision, and accuracy, forms the subject of the present article.

In advance of the general discussion it is not amiss to state the conclusions drawn as to these three points. It appears that when the conditions for the use of sodium oxalate have been defined they may be conformed to easily and no unusual apparatus or complex procedure is necessary. The accuracy obtainable is, within the limits of our present knowledge, sufficient for even the most refined work (see p. 64I), and the precision or agreement of duplicates is satisfactory. 
Along with such striking advantages we find certain disadvantages, but none of these appear serious. The more important are as follows:

(a) The largest sample which can be used ordinarily (for $50 \mathrm{cc}$ of $\mathrm{N} /$ ro $\mathrm{KMnO}_{4}$ ) is only 0.3 gram. This necessitates an accurate weighing in order to gain a high degree of accuracy. It is not desirable to use a standard stock solution, unless freshly prepared. If such solution is kept for a considerable length of time, it acts upon the glass of its container; it is also slowly decomposed by the action of light.

(b) The detection of small amounts of allied organic compounds in the sodium oxalate is rather difficult, except by comparison of the reducing value with that of other samples of known purity.

(c) The initial drying of the oxalate is subject to slight uncertainty, but once dried it is practically nonhygroscopic.

\section{INORMAL COURSE OF THE REACTION}

In I 866 Harcourt and Esson ${ }^{3}$ concluded from a study of the speeds of reaction under various conditions, that the steps of the reaction are as follows:

I. $2 \mathrm{Mn}(\mathrm{OH})_{7}+{ }_{5} \mathrm{H}_{2} \mathrm{C}_{2} \mathrm{O}_{4}=2 \mathrm{Mn}(\mathrm{OH})_{2}+\mathrm{TOCO}_{2}+\mathrm{ToH}_{2} \mathrm{O}$ (very slow)

II. $3 \mathrm{Mn}(\mathrm{OH})_{2}+2 \mathrm{Mn}(\mathrm{OH})_{7}=5 \mathrm{Mn}(\mathrm{OH})_{4}$ (very fast)

III. $\mathrm{Mn}(\mathrm{OH})_{4}+\mathrm{H}_{2} \mathrm{C}_{2} \mathrm{O}_{4}=\mathrm{Mn}(\mathrm{OH})_{2}+2 \mathrm{CO}_{2}+{ }_{2} \mathrm{H}_{2} \mathrm{O}$ (fast, but less so than II.)

Among the more recent articles presenting either experimental or theoretical evidence on this subject, the more important are those by Schillow ${ }^{4}$ and by Skrabal. ${ }^{5}$

From measurements of the speeds of reaction, the former presents the following system as representing the steps of the reaction:

I. $\mathrm{Mn}(\mathrm{OH})_{7}+{ }_{2} \mathrm{H}_{2} \mathrm{C}_{2} \mathrm{O}_{4}=\mathrm{Mn}(\mathrm{OH})_{3}+{ }_{4} \mathrm{CO}_{2}+{ }_{4} \mathrm{H}_{2} \mathrm{O}$ (very slow)

II. $\mathrm{Mn}(\mathrm{OH})_{3} \cdot 2 \mathrm{H}_{2} \mathrm{C}_{2} \mathrm{O}_{4}+\mathrm{Mn}(\mathrm{OH})_{7}=2 \mathrm{Mn}(\mathrm{OH})_{3}+{ }_{4} \mathrm{CO}_{2}+{ }_{4} \mathrm{H}_{2} \mathrm{O}$ (measured)

III. $\mathrm{Mn}(\mathrm{OH})_{3}+2 \mathrm{H}_{2} \mathrm{C}_{2} \mathrm{O}_{4}=\mathrm{Mn}(\mathrm{OH})_{3} \cdot 2 \mathrm{H}_{2} \mathrm{C}_{2} \mathrm{O}_{4}$ (practically instantaneous)

The second of these can be divided into two parts:

II, a. $\mathrm{Mn}(\mathrm{OH})_{3} \cdot 2 \mathrm{H}_{2} \mathrm{C}_{2} \mathrm{O}_{4}+\mathrm{Mn}(\mathrm{OH})_{7}=\mathrm{Mn}(\mathrm{OH})_{6}+\mathrm{Mn}(\mathrm{OH})_{4} \cdot \mathrm{H}_{2} \mathrm{C}_{2} \mathrm{O}_{4}$ (measured)

II,b. $\mathrm{Mn}(\mathrm{OH})_{4} \cdot 2 \mathrm{H}_{2} \mathrm{C}_{2} \mathrm{O}_{4}+\mathrm{Mn}(\mathrm{OH})_{6}=\mathrm{Mn}(\mathrm{OH})_{3}+{ }_{4} \mathrm{CO}_{2}+{ }_{4} \mathrm{H}_{2} \mathrm{O}$ (practically instantaneous)

${ }^{2}$ Philos. Trans., 156, p. 193; 1866. ' Ber., 86, p. 2735; 1903. '7s. anorg. Chem., 42, p. I; 1904. 
However, this author qualifies the proposed explanation by the following statements:

"This scheme is considered only as an approximate picture of the phenomenon and is true particularly for mean concentration of hydrogen ions and low temperatures $\left(0-25^{\circ}\right)$. Under other conditions, side reactions and disturbances enter in which can be partially observed or foreseen. ***

"In addition to the reactions given above, the following two also require consideration:

$$
\begin{aligned}
& \text { IV. }{ }_{2} \mathrm{Mn}(\mathrm{OH})_{3}+\mathrm{H}_{2} \mathrm{C}_{2} \mathrm{O}_{4}=2 \mathrm{Mn}(\mathrm{OH})_{2}+{ }_{2} \mathrm{CO}_{2}+{ }_{2} \mathrm{H}_{2} \mathrm{O} \\
& \text { V. }{ }_{4} \mathrm{Mn}(\mathrm{OH})_{2}+\mathrm{Mn}(\mathrm{OH})_{7}={ }_{5} \mathrm{Mnn}(\mathrm{OH})_{3}, "
\end{aligned}
$$

These last reactions, however, are not assigned a definite rôle in the general scheme.

After an extended series of experiments on the speed of the reaction under various conditions, Skrabal (loc. cit.) advances the following scheme as representing the course of the reaction.

Incubation period:

(I) $\mathrm{H}_{2} \mathrm{C}_{2} \mathrm{O}_{4}+\mathrm{KMnO}_{4}=\mathrm{Mn}^{2}+\mathrm{CO}_{2}$ (measurable)

(2) $\mathrm{H}_{2} \mathrm{C}_{2} \mathrm{O}_{4}+\mathrm{Mn} \cdots=\mathrm{Mn}(\mathrm{OH})_{2}+\mathrm{CO}_{2}$ (practically instantaneous)

Induction period:

(3) $\mathrm{Mn}(\mathrm{OH})_{2}+\mathrm{KMnO}_{4}=\mathrm{Mn}^{\cdots}$ (less rapidly)

(4) $\mathrm{Mn}^{\cdots}+\mathrm{H}_{2} \mathrm{C}_{2} \mathrm{O}_{4}=\mathrm{Mn}(\mathrm{OH})_{2}+\mathrm{CO}_{2}$ (practically instantaneous)

(5) $\mathrm{Mn}^{\cdots}+\mathrm{H}_{2} \mathrm{C}_{2} \mathrm{O}_{4}=\mathrm{Mn}(\mathrm{OH})_{3} \cdot \mathrm{H}_{2} \mathrm{C}_{2} \mathrm{O}_{4}$ (practically instantaneous)

(6) $\mathrm{Mn}^{\cdots}=\mathrm{Mn}(\mathrm{OH})_{2}+\mathrm{Mn}(\mathrm{OH})_{4}$ (practically instantaneous)

End period:

$$
\begin{aligned}
& \text { I. }\left\{\begin{array}{l}
\text { (7) } \mathrm{Mn}(\mathrm{OH})_{3} \cdot \mathrm{H}_{2} \mathrm{C}_{2} \mathrm{O}_{4}=\mathrm{Mn} \cdots \\
\text { (8) } \mathrm{H}_{2} \mathrm{C}_{2} \mathrm{O}_{4}+\mathrm{Mn} \cdots=\mathrm{Mn}(\mathrm{OH})_{2}+\mathrm{CO}_{2} \text { (practically instantaneous) }
\end{array}\right. \\
& \text { II. } \begin{cases}\text { (9) } \mathrm{Mn}(\mathrm{OH})_{2}+\mathrm{Mn}(\mathrm{OH})_{4}=\mathrm{Mn} \cdots \\
\text { (Io) } \mathrm{H}_{2} \mathrm{C}_{2} \mathrm{O}_{4}+\mathrm{Mn}^{\cdots}=\mathrm{Mn}(\mathrm{OH})_{2}+\mathrm{CO}_{2} \text { (practically instantaneous) }\end{cases}
\end{aligned}
$$

Since this last system of reactions is based upon elaborate experimental work, it can be accepted as probably best representing the normal course of the reaction. For the present considerations any one of the systems would serve equally well to explain the observed facts.

The variations from a normal course will be considered after the experimental part of the present work has been described. 


\section{EXPERIMENTAL PART}

\section{REAGENTS EMPLOYED}

The water and sulphuric acid employed were frequently tested for reducing matter and in each case were shown to be free from appreciable amounts of such impurities. The manganous sulphate was similarly tested for reducing and oxidizing influence and shown to be satisfactory. To purify the air used for the tests of Tables VI and VII, it was passed through cotton wool to remove dust and grease, bubbled through a solution of potassium hydroxide to take out any acid vapors present, and then through solutions of chromic acid and potassium permanganate. The purified air had no detectable reducing effect upon dilute solutions of permanganate under the conditions of titration.

The carbon dioxide used for the tests of Table VI was taken from a cylinder of the commercial liquid and passed through water, chromic acid, and permanganate solution before use. An analysis showed the presence of about 3 per cent of methane; but this gas seemed to have only a very slight reducing action on the permanganate in dilute solution, so that the results of the series in which it was used can be regarded as but slightly less reliable than the series in Table VII. For this latter group of tests, pure carbon dioxide was made from acid and soda. This source gave a gas which had no detectable reducing action under the conditions of its use.

The potassium permanganate used for most of the work was a sample of good quality which had been made up in normal solution for over six months before filtration and dilution to tenth normal strength for use. The diluted solution was filtered frequently through asbestos to insure freedom from precipitated manganese dioxide. For the series of tests reported in Table IV, b, a second permanganate was used. In this case the strong solution was boiled for a few minutes, cooled, filtered, and diluted to tenth normal strength. For the series of Table VII still a different permanganate was employed, this stock being prepared in the same manner as the main solution. About 40 grams of solution were used for each titration. 
The sodium oxalate used for all of the experiments except those of Table IV, $b$, was a sample specially purified in this laboratory by Mr. J. B. Tuttle. It is sufincient to state here that all tests indicated a total impurity of not over 0.05 per cent. For the tests of Table IV, b, another sample of sodium oxalate, made by the Mallinckrodt Chemical Works especially for our use, was employed. This material was shown by test to be as pure as that prepared in our own laboratory.

\section{WEIGHING OF OXALATE AND PERMANGANATE USED}

Since in all of the work described in the following part of this article only comparative values were required, the absolute amount of oxalate employed in any one test was not of importance as long as the relative amounts present in the experiments of a series were accurately known. Therefore it was found desirable to use about 20-gram portions of a N/5 stock solution of the oxalate for each test. Each such sample was weighed from a burette to the nearest $5 \mathrm{mg}$; the relative wieght of each sample was thus determited to better than I part in 2000 in less time and with greater certainty than would have been possible by weighing out the dried powder.

In order to prevent any change in the strength of the stock solution from affecting the conclusions drawn from the results of any series of titrations, only those values obtained during a period of a few days are compared with each other. This plan avoided any uncertainty due either to slow decomposition of the oxalate in solution occurring through action on the glass of the container, or oxidation by the air through the aid of light, or to change in oxidizing value of the permanganate solution employed.

The measurement of the permanganate solution was accomplished by the use of a weight burette. For this work this form of instrument possesses the following advantages: (a) Correction for the temperature changes which affect the volume of the solution is not necessary; $(b)$ completeness or uniformity of running down of the solution from the burette walls is unessential; and (c) the solution can be weighed readily to o.or $\mathrm{g}$ ( $\mathrm{I}$ part in 5000 on a $50-\mathrm{g}$ sample), whereas measurement to o.or cc is exceedingly 
uncertain. The freedom from errors due to temperature changes is of great importance in this work, as the burette is often very appreciably warmed by the steam rising from the hot liquid undergoing titration.

The burette used was made from a 50 cc cylindrical separatory funnel by drawing down the stem to the form of an ordinary burette tip. For exact work it has been found desirable to have this tip so drawn down that it will deliver about Io cc per minute or 0.03 cc per drop.

\section{EFFECT OF CONDITIONS UPON THE RESULT OF A TITRATION}

The ordinary procedure for the use of sodium oxalate in the standardization of potassium permanganate, is as follows: Dissolve about a quarter of a gram of the oxalate in $250 \mathrm{cc}$ of water, acidify with sulphuric acid, warm to $70^{\circ}$, and titrate to the first permanent pink.

It was desirable to determine the effect of the variation of the following conditions upon the result obtained, viz, temperature, acidity, volume of solution, rate of addition of the permanganate, access of air, presence of added manganous sulphate and in connection with these, the corrections necessary upon the apparent end points. In order to accomplish such determination, the factors were varied one at a time, noting the difference, if any, produced upon the apparent value of the permanganate. The results of the titrations are reported as the ratios of the oxalate used to the permanganate used multiplied by $\mathrm{IO}^{-2}$. These values are proportional to, and, indeed, numerically almost equal to, the iron value of the permanganate. Therefore, for purposes of discussion the values are treated as if they were the iron value of the permanganate, expressed in grams of iron per gram of solution. It should be noted that an increase in the iron value represents a decrease in the permanganate consumed, and vice versa. A variation of $0.0 \mathrm{I} \mathrm{cc}$ in the amount of permanganate used in a titration is approximately equivalent to a change of one unit in the last expressed figure of the iron value. 
(a) END-POINT CORRECTIONS

In a recent article Dr. W. C. Bray ${ }^{6}$ has suggested the necessity for the correction of the apparent end point obtained in the reaction of oxalic acid and permanganate, and has recommended that the correction be determined as follows: After reaching the end point the solution is cooled to room temperature, potassium iodide solution is added, and the iodine liberated is at once titrated with dilute $(\mathrm{N} / 5 \mathrm{O})$ sodium thiosulphate.

In order to test the necessity and the accuracy of this method under the various conditions of titration, we examined experimentally the following points:

(a) Does the equivalent in oxidizing power of the permanganate excess remain in the solution long enough to allow the necessary cooling before the titration with thiosulphate?

(b) Does the thiosulphate titration give the total permanganate excess used to produce the end point, or does it indicate only the permanganate which remains in the solution as such?

(c) Does the depth of the pink color at the end of the titration show how great an excess of permanganate has been added in order to produce that end point?

Before applying the method of correction proposed by Bray, it is necessary to cool the solution to room temperature. Therefore, if, as is desirable, the permanganate end point is obtained while the solution is hot, some time must elapse during cooling and it is possible that a loss of oxidizing (or iodine liberating) power would occur, which loss would render the correction as subsequently determined valueless. This point was tested by determining the residual oxidizing power of solutions to which had been added known amounts of permanganate at various temperatures $\left(30-90^{\circ}\right)$, with varying acidities (2-ro per cent by volume $\mathrm{H}_{2} \mathrm{SO}_{4}$ ) and with the addition of various amounts of manganous sulphate (up to $\mathrm{r} g$ $\mathrm{MnSO}_{4} \cdot 4 \mathrm{H}_{2} \mathrm{O}$ ). These experiments showed that no appreciable loss occurred within a period of one-half hour, if only a small 
amount of permanganate $(0.02-0.20 \mathrm{cc}$ of $\mathrm{N} / \mathrm{IO}$ solution) is added to any such solution. Moreover this condition was found to exist even when the permanganate was wholly decolorized by reaction with the manganous salt. The full oxidizing power was then retained in the solution, probably in the tri- or tetra-valent manganese salts $\left(\mathrm{Mn}^{\cdots}\right.$ or $\left.\mathrm{Mn}^{\cdots \cdot}\right)$. The lapse of 5 to ro minutes necessary for cooling the solution to room temperature, is thus shown to be without influence; and it is evident that the procedure described determines not only the permanganate remaining in the solution as such, but also that which was not completely reduced to the manganous condition.

The procedure described by Bray has been accepted on the above basis as giving a determination of the real excess of permanganate which was added to produce the end point. However, the question as to the difference between this end-point correction and that determined by the depth of the pink color at the end point, must be considered on a different basis.

For each of the titrations made in this investigation, two values were obtained, the one using the color method, the other the iodine method for correction of the total permanganate added. In several of the following tables both of these values are reported. By inspection of these data (Tables II, III, and V) it will be apparent that, in general, the color correction and the iodine correction differ by no more than $0.02 \mathrm{cc}_{2}$ except when the end point was reached with the solution at temperatures below $35^{\circ}$, or when the permanganate solution was added rapidly just at the end point. This was true in all but 6 of over 200 tests; and even in these the difference between the two corrections was not more than $0.04 \mathrm{cc}$. It is therefore certain that if the end point is approached slowly in a solution above $60^{\circ}$, the depth of color will be proportional to the total excess of permanganate added, i. e., no permanganate will be decolorized without at the same time being completely reduced to the manganous condition. However, at lower temperatures, in the presence of much sulphuric acid (more than 5 per cent by volume), and particularly with 
rapid addition of permanganate or with insufficient stirring just preceeding the end point, the amount of permanganate decolorized but not wholly reduced to the manganous condition, easily may be as much as o.I cc.

\section{(b) RATE OF ADDITION OF THE PERMANGANATE}

The rate of the addition of the permanganate solution in the titration of iron in solutions containing chlorides has been shown to have considerable effect upon the result obtained. ${ }^{7}$ The influence of this factor upon the oxalate-permanganate reaction was, therefore, studied.

The influence of varying the amount of permanganate added before the quick color change of rapid reduction began was first tested. This factor has an influence only at low temperatures (below $40-50^{\circ}$ ), as at any higher temperature the reduction proceeds rapidly from the very start. Tests made at $30^{\circ}$ in 5 per cent sulphuric-acid solution gave results as follows:

Amount of $\mathrm{KMnO}_{4}$ added before rapid decolorization was evident. . Results obtained (strength of

$\begin{array}{rrrrr}\left.\mathrm{KMnO}_{4}\right) \ldots \ldots \ldots \ldots \ldots \ldots \ldots \ldots & 0.005936 & 0.005936 & 0.00593^{2} & 0.005929 \\ 37 & 35 & 33 & . \\ 34 & 37 & & \end{array}$

These results show that the addition of large amounts of permanganate before rapid oxidation of the oxalate begins tends to give lower values for the permanganate solution, i. e., to cause a larger consumption of permanganate. The influence of this factor is small, but it is of some significance, as will be apparent from the later discussion.

${ }^{7}$ A. Skrabal: Zs. anal. Chem., 42, p. 359; 1903. A. N. Friend: J. Chem. Soc. (London), 95, p. x228; igsg. Jones and Jeffrey, Analyst, 34, p. 306; 1909. 


\section{TABLE I}

Effect of Rate of Addition of Permanganate During Main Part of Titration

\begin{tabular}{|c|c|c|c|c|}
\hline Experiment No. & $\begin{array}{l}\text { Acidity, volume } \\
\text { per cent } \mathrm{H}_{2} \mathrm{SO}_{4}\end{array}$ & Temperature & $\begin{array}{l}\text { Time for titration } \\
\text { (minutes) }\end{array}$ & $\begin{array}{l}\text { Result, corrected iron } \\
\text { value }\end{array}$ \\
\hline $\begin{array}{l}118 \\
120 \\
119 \\
125 \\
129 \\
121 \\
123 \\
122 \\
124 \\
230 \\
231 \\
206 \\
223 \\
207 \\
225 \\
226 \\
232 \\
233 \\
208 \\
209 \\
227 \\
229\end{array}$ & 5 & $\begin{array}{l}80^{\circ} \\
30^{\circ}\end{array}$ & $\begin{array}{c}5 \\
5 \\
827 \\
9120 \\
9120 \\
7 \\
6 \\
837 \\
9120 \\
0.5 \\
0.5 \\
5 \\
4 \\
5 \\
860 \\
860 \\
0.5 \\
0.5 \\
5 \\
5 \\
830 \\
830\end{array}$ & $\begin{array}{r}0.005945 \\
45 \\
46 \\
56 \\
56 \\
0.005942 \\
42 \\
44 \\
44 \\
0.005592 \\
92 \\
92 \\
93 \\
91 \\
94 \\
95 \\
0.005589 \\
88 \\
98 \\
5600 \\
00 \\
5598\end{array}$ \\
\hline
\end{tabular}

8 Dropwise with stirring.

Intermittent, without continuous stirring.

After the initial reduction of 3 -Io cc of permanganate the rate of addition of the main portion of the permanganate was varied, giving the results listed in Table $I$. These experiments indicate that except on long standing at a high temperature (after starting the reaction), or with a very rapid addition of permanganate to a weakly acid solution at a high temperature, the rate of the addition of the permanganate during the main part of the titration has no influence. The high values obtained in experiments 125 and 129 are probably due to oxidation of the oxalic acid by the air, and the low values of experiments 232 and 233 show a loss of oxygen, because of the excessive rate of the permanganate addition. 
The effect of the rate of the addition of the permanganate just at the end point, has already been suggested (p.620), but the following data will make this point clearer. In each pair of tests the only variable was the rate of the addition of the permanganate solution just before the end point. Only the two experiments in each group may be compared. (See Table II.)

In the first part of Table II some rather extreme cases (experiments done at $30^{\circ}$ ) have been chosen to show how large the error of the apparent end point may be, without any influence upon the corrected value. In cases where much smaller corrections were necessary (temperature $60^{\circ}$ and above) the agreement of uncorrected values was better, regardless of the speed at which the end point was approached. The latter part of Table II shows this agreement of the uncorrected values at the higher temperature. Nevertheless, it is not desirable to approach the end point so rapidly as to make a correction larger than o.I cc necessary.

\section{TABLE II}

Effect of Rate of Addition of Permanganate at the End Point

[In the first of each pair of experiments the end point was approached slowly, in the second rapidly]

\begin{tabular}{|c|c|c|c|c|c|c|}
\hline \multirow{2}{*}{ Temperature } & \multirow{2}{*}{$\begin{array}{c}\text { Acldity, } \\
\text { volume } \\
\text { per cent } \\
\mathrm{H}_{2} \mathrm{SO}_{4}\end{array}$} & \multirow{2}{*}{ Color blank } & \multirow{2}{*}{ Iodine blank } & \multicolumn{3}{|c|}{ Value of permanganate } \\
\hline & & & & Uncorrected & $\begin{array}{l}\text { Color } \\
\text { corrected }\end{array}$ & $\begin{array}{c}\text { Iodine } \\
\text { corrected }\end{array}$ \\
\hline \multirow{2}{*}{$30^{\circ}$} & \multirow{2}{*}{2} & 0.01 & 0.03 & 0.005584 & 0.005586 & 0.005589 \\
\hline & & .25 & .34 & 37 & 71 & 87 \\
\hline \multirow{2}{*}{$30^{\circ}$} & \multirow{2}{*}{5} & .03 & .09 & .005929 & .005933 & .005942 \\
\hline & & .15 & .39 & 5894 & 12 & 42 \\
\hline \multirow{2}{*}{$30^{\circ}$} & \multirow{2}{*}{5} & .05 & .085 & .005030 & .005034 & .005037 \\
\hline & & .08 & .19 & 17 & 26 & 38 \\
\hline \multirow{2}{*}{$30^{\circ}$} & \multirow{2}{*}{5} & .04 & .08 & .005923 & .005929 & .005935 \\
\hline & &.- & .51 & 5871 & - & 37 \\
\hline \multirow{2}{*}{$30^{\circ}$} & \multirow{2}{*}{10} & .06 & .11 & .005636 & .005642 & .005648 \\
\hline & & .08 & .14 & 33 & 43 & 50 \\
\hline \multirow{2}{*}{$60^{\circ}$} & \multirow{2}{*}{2} & .05 & .05 & .005642 & .005649 & .005649 \\
\hline & & .03 & .05 & 45 & 49 & 51 \\
\hline \multirow{2}{*}{$60^{\circ}$} & \multirow{2}{*}{5} & .05 & .07 & .005638 & .005646 & .005649 \\
\hline & & .05 & .06 & 40 & 44 & 46 \\
\hline \multirow{2}{*}{$83^{\circ}$} & \multirow{2}{*}{2} & .06 & .07 & .005642 & .005650 & .005651 \\
\hline & & .06 & .06 & 45 & 52 & 52 \\
\hline \multirow{2}{*}{$96^{\circ}$} & \multirow{2}{*}{2} & .05 & .04 & .005647 & .005652 & .005651 \\
\hline & & .2 & .15 & 33 & 61 & 54 \\
\hline
\end{tabular}




\section{(c) VOLUME OF THE SOLUTION}

The volume of the solution in which the titration is made might affect the rate of the reaction and, therefore, possibly the result of the titration. Tests were made of this point by varying the initial volume in a series of titrations made at $90^{\circ}$ in solutions containing 5 per cent by volume of sulphuric acid. The results were as follows:

$\begin{array}{lrrrrr}\text { Initial volume ....... } 50 \mathrm{cc} & 250 \mathrm{cc} & 500 \mathrm{cc} & 700 \mathrm{cc} & \text { I000 cc } \\ \text { Values obtained....... } & 0.005 \mathrm{I} 39 & 0.005 \mathrm{I} 39 & 0.005 \mathrm{I} 36 & 0.005 \mathrm{I} 33 & 0.005^{\mathrm{I} 27} \\ & 36 & 39 & 34 & 32 & 29 \\ & & 37 & & & \end{array}$

By increasing the initial volume beyond $250 \mathrm{cc}$, the resulting value for the permanganate solution is markedly decreased. That this is due to the change in the initial concentration of the oxalate is indicated by the results obtained in two titrations in which the initial volume was rooo cc but the amount of oxalate used was increased threefold, thus making its initial concentration about that ordinarily resulting in an initial volume of $350 \mathrm{cc}$. The results thus obtained were 0.005136 and $0.005^{1} 36$.

At $30^{\circ}$ the initial rate of the permanganate reduction is so much. less than at $90^{\circ}$, that it is not possible to note the effect of initial volume free from this influence. A few results were obtained as follows:

Initial volume . . . . . . . $5 \ldots \ldots \ldots \ldots \ldots \ldots . \ldots \ldots$

Values obtained . . . . . . . . . . . . . . . . 0.005943

45

$250 \mathrm{cc} \quad 1000 \mathrm{cc}$

०. $005942 \quad 0.005945$

42

In these experiments no decided effect of volume is to be found.

It should be noted that in each of these cases the change in volume had no effect upon the concentration of the sulphuric acid present.

\section{(d) ACIDITY AND TEMPERATURE}

The effects of acidity and of temperature were investigated by two series of experiments, the results of which are given in Tables III and IV. These data show that either higher temperature or less concentration of sulphuric acid tends to give higher values for the permanganate, i. e., to reduce the amount of permanganate required. These effects are not large and, indeed, the results 
obtained in some cases show duplicates as discordant as experiments carried out under somewhat different conditions; nevertheless, the tendency in the two directions is rather convincing that these factors have a real influence upon the results obtained. The importance of even such slight variations is considerable, as will be apparent from the discussion later.

It will be seen from the data of Table IV that the first series exhibits a larger apparent influence of temperature than the second series reported. This is due to the greater care exercised in the latter series to stir the solution very vigorously and to add the permanganate more slowly, particularly at the beginning and end of each titration. However, the first series shows better the variation which may be expected if only ordinary titration precautions are observed.

TABLE III

Effect of Acidity and Temperature

\begin{tabular}{|c|c|c|c|c|c|c|}
\hline \multirow{2}{*}{ Temperature } & \multirow{2}{*}{$\begin{array}{l}\text { Acidity, } \\
\text { volume per } \\
\text { cent } \mathrm{H}_{2} \mathrm{SO}_{1}\end{array}$} & \multirow{2}{*}{ Color blank } & \multirow{2}{*}{ Iodine blanis } & \multicolumn{3}{|c|}{ Value of permanganate } \\
\hline & & & & Uncorrected & $\begin{array}{l}\text { Color } \\
\text { corrected }\end{array}$ & $\begin{array}{l}\text { Iodine } \\
\text { corrected }\end{array}$ \\
\hline \multirow{6}{*}{$30^{\circ}$} & 2 & 0.04 & 0.06 & 0.005129 & 0.005135 & 0.005137 \\
\hline & 2 & .04 & .05 & 33 & 38 & 39 \\
\hline & 5 & .04 & .05 & 27 & 32 & 34 \\
\hline & 5 & .03 & .035 & 27 & 31 & 31 \\
\hline & 10 & .05 & .10 & 18 & 25 & 32 \\
\hline & 10 & .02 & .09 & 21 & 24 & 33 \\
\hline \multirow{7}{*}{$45^{\circ}$} & 2 & .02 & .03 & .005134 & .005136 & .005138 \\
\hline & 2 & .03 & .04 & 34 & 38 & 40 \\
\hline & 5 & .03 & .04 & 30 & 34 & 35 \\
\hline & 5 & .03 & .025 & 30 & 37 & . 36 \\
\hline & 10 & .01 & .03 & 35 & 36 & 39 \\
\hline & 10 & .03 & .03 & 31 & 35 & 35 \\
\hline & 10 & .02 & .035 & 37 & 40 & 42 \\
\hline \multirow{4}{*}{ - } & 2 & .02 & .02 & .005129 & .005132 & .005132 \\
\hline & 2 & .03 & .03 & 36 & 40 & 40 \\
\hline & 2 & .035 & .035 & 33 & 37 & 37 \\
\hline & 2 & .04 & .05 & 35 & 41 & 42 \\
\hline \multirow[t]{5}{*}{$60^{\circ}$} & 5 & .04 & .06 & 26 & 32 & 46 \\
\hline & 5 & .05 & .05 & 32 & 39 & 39 \\
\hline & 10 & .05 & .05 & 33 & 40 & 40 \\
\hline & 10 & .03 & .05 & 33 & 37 & 40 \\
\hline & 10 & .02 & .04 & 34 & 38 & 40 \\
\hline
\end{tabular}


TABLE III-Continued

Effect of Acidity and Temperature-Continued

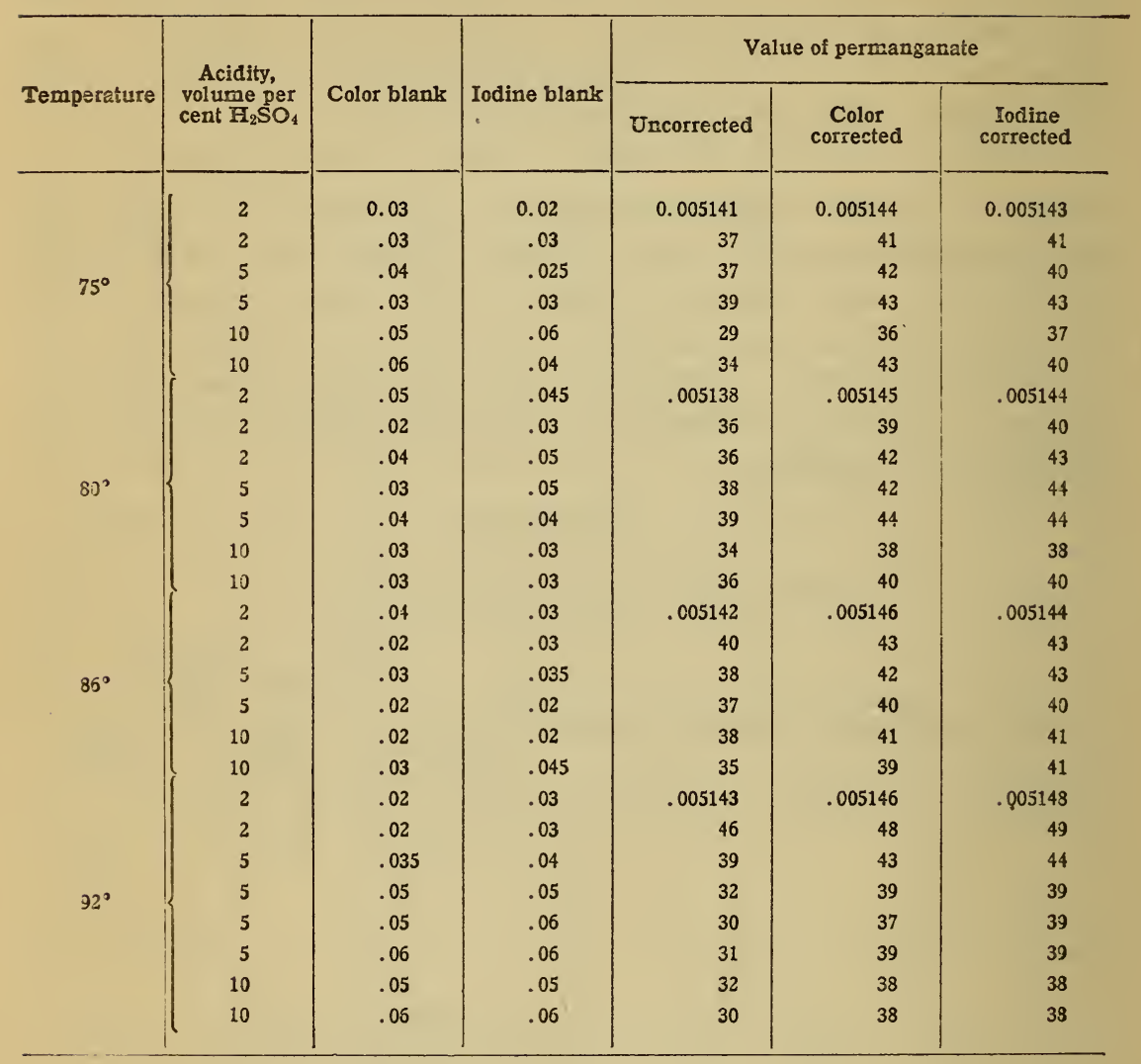


TABLE IV

Effect of Acidity and Temperature

(a) SERIES 1, REARRANGEMENT OF DATA OF TABLE III

[Each value reported is the average of at least two determinations]

\begin{tabular}{c|r|r|r}
\hline \multirow{2}{*}{ Temperature } & \multicolumn{3}{|c}{ Acidity, volume per cent $\mathrm{H}_{2} \mathrm{SO}_{4}$} \\
\cline { 2 - 4 } & 2 per cent & 5 per cent & 10 per cent \\
\hline $30^{\circ}$ & 0.005138 & 0.005133 & 0.005132 \\
$45^{\circ}$ & 39 & 35 & 38 \\
$60^{\circ}$ & 38 & 42 & 40 \\
$75^{\circ}$ & 42 & 42 & 38 \\
$80^{\circ}$ & 42 & 44 & 39 \\
$86^{\circ}$ & 44 & 40 & 41 \\
$92^{\circ}$ & 48 & 38 \\
\hline
\end{tabular}

(b) SERIES 2

\begin{tabular}{c|r|r|r}
\hline $30^{\circ}$ & 0.005646 & 0.005646 & 0.005649 \\
$60^{\circ}$ & 50 & 48 & 48 \\
$80^{\circ}$ &. & 50 & $\cdots$ \\
$85^{\circ}$ & 51 & 50 & 44 \\
$92^{\circ}$ &.- & 50 &. \\
$95^{\circ}$ & 53 & 52 & 46 \\
\hline
\end{tabular}

In addition to the data of Tables III and IV, those in other tables will show the same influence of temperature and acidity as are here indicated. Taking these data all together, it is certain that, though small, these influences are appreciable.

The time in the titration at which the tempertaure has an influence upon the result is evident from the tests of Table V. These data show that, except in its influence upon the size of the end-point correction, the temperature of the solution after the first few $\mathrm{cc}$ of the permanganate have been decolorized is without appreciable effect. The significance will be apparent when considered in connection with the results of the tests given in Table VIII. 


\section{TABLE V}

Time at which Temperature has Effect

[All titrations started in $250 \mathrm{cc}$ of 5 per cent by volume sulphuric acid]

\begin{tabular}{|c|c|c|c|c|c|c|c|}
\hline \multirow{2}{*}{\multicolumn{3}{|c|}{$\begin{array}{l}\text { Temperature: (a) Initial, (b) during } \\
\text { main part of titration, (c) at end } \\
\text { point }\end{array}$}} & \multirow{3}{*}{$\begin{array}{c}\begin{array}{c}\text { Color } \\
\text { blank }\end{array} \\
0.05\end{array}$} & \multirow{3}{*}{$\begin{array}{c}\begin{array}{c}\text { Iodine } \\
\text { blank }\end{array} \\
0.06\end{array}$} & \multicolumn{3}{|c|}{ Value of permanganate } \\
\hline & & & & & \multirow{2}{*}{$\begin{array}{c}\text { Uncorrected } \\
0.005130\end{array}$} & \multirow{2}{*}{$\begin{array}{c}\begin{array}{c}\text { Color } \\
\text { corrected }\end{array} \\
0.005137\end{array}$} & \multirow{2}{*}{$\begin{array}{c}\begin{array}{c}\text { Iodine } \\
\text { corrected }\end{array} \\
0.005139\end{array}$} \\
\hline (a) & (b) & $(c)$ & & & & & \\
\hline $90^{\circ}$ & $90^{\circ}$ & $90^{\circ}$ & .06 & .06 & 31 & 39 & 39 \\
\hline \multirow{2}{*}{$90^{\circ}$} & \multirow{2}{*}{$90^{\circ}$} & \multirow{2}{*}{$30^{\circ}$} & .03 & .07 & 29 & 33 & 38 \\
\hline & & & .03 & .065 & 30 & 34 & 39 \\
\hline \multirow{3}{*}{$90^{\circ}$} & \multirow{3}{*}{$30^{\circ}$} & \multirow{3}{*}{$30^{\circ}$} & .03 & .09 & 25 & 29 & 37 \\
\hline & & & .04 & .12 & 19 & 24 & 35 \\
\hline & & & .03 & .05 & .005126 & .005130 & .005133 \\
\hline \multirow[t]{3}{*}{$30^{\circ}$} & \multirow[t]{3}{*}{$30^{\circ}$} & \multirow[t]{3}{*}{$30^{\circ}$} & .05 & .08 & 24 & 32 & 36 \\
\hline & & & .04 & .085 & 22 & 27 & 32 \\
\hline & & & .05 & .06 & 25 & 31 & 33 \\
\hline \multirow{3}{*}{$30^{\circ}$} & \multirow{3}{*}{$30^{\circ}$} & \multirow{3}{*}{$90^{\circ}$} & .07 & .09 & 25 & 34 & 36 \\
\hline & & & .05 & .05 & 25 & 30 & 30 \\
\hline & & & .04 & .05 & 29 & 34 & 34 \\
\hline \multirow{2}{*}{$30^{\circ}$} & \multirow{2}{*}{$90^{\circ}$} & \multirow[t]{2}{*}{$90^{\circ}$} & .03 & .03 & 29 & 34 & 34 \\
\hline & & & .03 & .03 & 31 & 35 & 35 \\
\hline
\end{tabular}

(e) AIR ACCESS-OXIDIZING EFFECT

It has been suggested ${ }^{10}$ that during the course of the reaction atmospheric oxygen, through the carrying action of the manganous salt, might cause the oxidation of appreciable amounts of oxalic acid. To test this point, a preliminary series of experiments was made as to the results obtained on the removal of the larger part of the air from the titration vessel. To accomplish this, the solution to be titrated was made up in a flask with recently boiled water and a small amount of sodium carbonate was added just before starting the titration. The carbon dioxide evolved carried out the bulk of the air, and the flask was kept stoppered and the permanganate run in through a small funnel, which passed through the stopper. From the results it appeared that no oxidizing action of the air was to be feared, but to further test this point the following method was employed:

${ }_{10}$ Who first suggested this is not known; Schröder has tested this point recently (Zs. öffentliche Chem., 16, p. 270; r9ro). See p. 634 for discussion of his data. 
The solution to be titrated was placed in a glass-stoppered flask of special form (see Fig. I), and a strong current of air or carbon dioxide, as desired, was bubbled through the liquid before commencing the titration and during its progress. When carbon dioxide was used, the solution was heated to boiling and then cooled to the desired temperature in a stream of the gas, thus insuring the absence of all but the last traces of air.

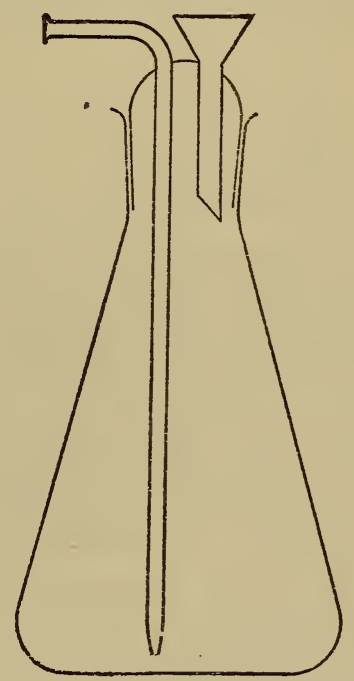

Fig. 1

The two series of tests made in this manner are summarized in Tables VI and VII.

\section{TABLE VI}

Effect of Access of Air on Titration

[All titrations started in $250 \mathrm{cc}$ of 5 per cent by volume sulphuric acid]

\begin{tabular}{c|c|c|c}
\hline Temperature & $\begin{array}{c}\text { Titration in flask with air } \\
\text { bubbled through solution }\end{array}$ & $\begin{array}{c}\text { Titration in flask with car- } \\
\text { bon dioxide 11 } \\
\text { through solution }\end{array}$ & $\begin{array}{c}\text { Titration in beaker } \\
\text { open to air, as in ordi- } \\
\text { nary procedure }\end{array}$ \\
\hline $30^{\circ}$ & $\left\{\begin{aligned} 0.005041 \\
40\end{aligned}\right.$ & 0.005037 & 0.005040 \\
$40^{\circ}$ & 42 & 38 & 39 \\
42 & 40 & 41 \\
42 & 43 & 40 \\
41 & 51 & 41 \\
\hline
\end{tabular}

11 The carbon dioxide used in the experiments of Table VI was found to contain 3 per cent of methane. See p. 616 . 
TABLE VII

Effect of Access of Air on Titration

[All titrations started in $250 \mathrm{cc}$ of 2 per cent by volume sulphuric acid]

\begin{tabular}{|c|c|c|c|}
\hline Temperature & $\begin{array}{l}\text { Titration in flask with air } \\
\text { bubbled through solution }\end{array}$ & $\begin{array}{l}\text { Titration in flask with car- } \\
\text { bon dioxide bubbled } \\
\text { through solution }\end{array}$ & $\begin{array}{l}\text { Titration in beaker } \\
\text { open to air, as in ordi- } \\
\text { nary procedure }\end{array}$ \\
\hline \multirow{2}{*}{$30^{\circ}$} & 0.005591 & 0.005592 & 0.005591 \\
\hline & 91 & 93 & 92 \\
\hline \multirow{2}{*}{$60^{\circ}$} & 94 & 99 & 97 \\
\hline & 94 & 99 & 97 \\
\hline \multirow{2}{*}{$90^{\circ}$} & 94 & 5600 & 98 \\
\hline & 95 & 01 & $5 \in A 2$ \\
\hline
\end{tabular}

The data of Tables VI and VII show that no large error comes from atmospheric oxidation of the oxalate during titration. The largest difference between results obtained using air and using carbon dioxide are only I part in 500 ( 0.2 per cent), and the differences were usually less than one-half this amount. Moreover, if carried out in a beaker, as ordinarily done, the values obtained are not appreciably different from those where air is wholly excluded (cf. last two columns of Table VII); and even when air is bubbled through the solution during a titration at $90^{\circ}$ the oxidation is scarcely appreciable. No such chance for atmospheric action is met with under the ordinary conditions of titration, since when following the usual procedure the carbon dioxide formed during the reaction prevents much oxygen from the air remaining in the solution during the reaction.

One other point tested was the effect of time elapsing before the beginning of the titration. Four samples were made up to $250 \mathrm{cc}$ with 5 per cent by volume sulphuric acid and heated to $90^{\circ}$. Two were titrated at once, the other two after standing an hour at $90^{\circ}$. The four results agreed within I in 5500 , showing that even under these rather severe conditions oxalic acid is sufficiently stable and nonvolatile to prevent loss during a titration from oxidation (in the absence of manganous salts, at least) from decomposition by the sulphuric acid, or from volatilization with the steam. 
As a further proof that atmospheric oxidation is not an important factor in the oxalate titration, the effect of the rate of titration.may be cited. In the data of Table I the titrations covering a period up to one hour show almost no tendency to give higher values. This is contrary to what might be expected if oxidation were taking place, as the oxidation occurring would naturally be, at least roughly, proportional to the time elapsed, and such is not the case. Experiments 125 and I 29 are the only exceptions met with. (See Table I.)

(f) PRESENCE OF ADDED MANGANOUS SULPEATE

Since the presence of added manganous sulphate would probably influence the initial rate of the reaction, its effect upon the result of the titration was tested. A series of tests (all but the last two at $30^{\circ}$ ) was carried out with the addition of manganous sulphate at different points in the course of the reaction. One cc of the solution of manganous sulphate added was equivalent to the manganous salt formed by the reduction of Io cc of the permanganate solution. The results of these experiments are given in Table VIII.

It appears from these data that unless the $\mathrm{MnSO}_{4}$ be added before the beginning of the titration it has little effect upon the result obtained. However, if even a small amount is added before starting the reaction at $30^{\circ}$, the value obtained is the same as is ordinarily obtained at $90^{\circ}$ without the addition of manganous salt. Addition before titration at $90^{\circ}$ has no influence. 


\section{TABLE VIII}

Effect of Added Manganous Sulphate

[All but last two tests at $30^{\circ}$, last two at $90^{\circ}$; all started in 250 cc of 5 per cent by volume sulphuric acid]

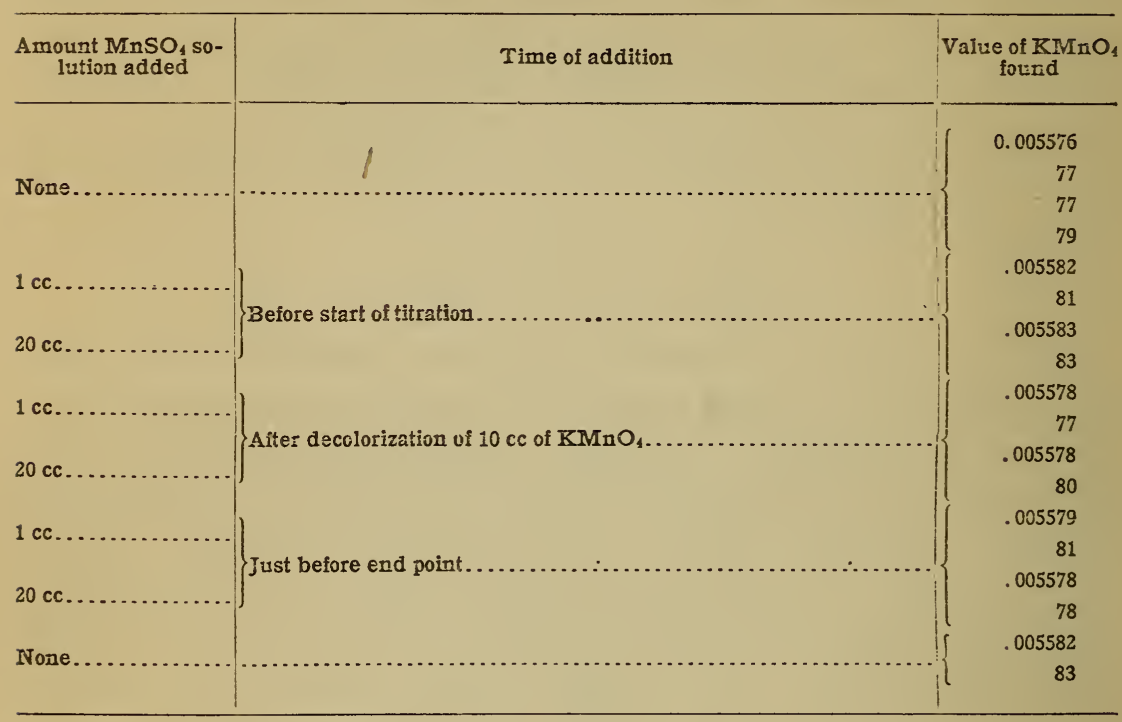

\section{DISCUSSION AND CONCLUSIONS}

\section{REVIEW OF POSSIBLE ERRORS}

As the standardization procedure consists in solution of a weighed sample in dilute sulphuric acid and direct titration with permanganate, any error occurring must be due either to error in weighing of oxalate or measuring of the permanganate or to a variation of the reaction itself from the form usually given, viz:

$$
5 \mathrm{H}_{2} \mathrm{C}_{2} \mathrm{O}_{4}+2 \mathrm{KMnO}_{4}+{ }_{3} \mathrm{H}_{2} \mathrm{SO}_{4}=\mathrm{K}_{2} \mathrm{SO}_{4}+2 \mathrm{MnSO}_{4}+\mathrm{IOCO}_{2}+8 \mathrm{H}_{2} \mathrm{O}
$$

Since, as already indicated (p. 6r 7), there is no necessity for an error in either the weighing of the oxalate or the measuring of the permanganate greater than I part in 2000 , only the irregularities of the reaction need be considered at length.

The variations of the reaction from its normal course may tend to cause the use of an excess of either permanganate or oxalate, 
or both sorts of influences may operate at the same time, in equal or unequal degree. There are nine possibilities of such irregularity; the first five of these would cause too small a consumption of permanganate, the next two an excessive use of it, and the last two might cause either of these effects. These possible sources of error are: (a) Loss of oxalic acid by volatilization from the solution; (b) decomposition of oxalic acid by water; (c) decomposition of oxalic acid by sulphuric acid; $(d)$ oxidation of oxalic acid by contact of the solution with the air; $(e)$ presence of oxalic acid unoxidized at the end point; $(f)$ liberation of oxygen during the reaction; $(g)$ presence at the end point of unreduced permanganate or other compounds of manganese higher than manganous; $(h)$ presence of impurities in the oxalate, either of greater or less reducing power power than the oxalate; $(i)$ formation of other products of oxidation than carbon dioxide and water.

\section{(a) LOSS OF OXALIC ACID BY VOLATILIZATION}

The fact that oxalic acid is readily volatile alone suggests the danger of loss from its solution by vaporization with steam. However, from the dilute solutions employed for titration purposes, no such losses occur, as has already been shown. The results obtained after an hour's standing at $90^{\circ}$ in 5 per cent sulphuric acid solution showed (p.63o) that no loss of oxalic acid had occurred. Similarly when titration extended over a period of one hour (Table I, p. 622) or when carbon dioxide or air was bubbled through the solution (Tables VI and VII, pp. 629-630) no such higher values of the permanganate were obtained as would have resulted had volatilization of the oxalic acid occurred. From these results it is apparent that no appreciable vaporization of oxalic acid will take place during the course of an ordinary titration which lasts, at the most, only 5 to ro minutes.

(b), (c) DECOMPOSITION OF OXALIC ACID BY WATER OR DY SULPHURIC ACID

The same data which have shown that no volatilization occurs also prove that the water and sulphuric acid had not caused a decomposition of the oxalic acid. These possible errors can, 
therefore, be considered improbable under any ordinary conditions of titration.

The experiments reported by Carles ${ }^{12}$ from which he was led to state that at $100^{\circ}$ oxalic acid in sulution is slowly decomposed with the formation of carbon dioxide and formic acid are not confirmed by our experiments. If such decomposition does take place, it is so slow as to have no appreciable infuence upon the results of a titration made at $90^{\circ}$ or below.

\section{(d) OXIDATION OF THE OXALIC ACID BY TEE AIR}

Schroeder ${ }^{13}$ has shown that in the presence of manganous sulphate oxalic acid solutions are oxidized by the air at an appreciable speed. This author presents a large amount of experimental data, from which he draws very decided conclusions. Those which are of importance in the present discussion are as follows (numbered as in original):

(3) In the oxidation of oxalic acid by potassium permanganate, an error (too little $\mathrm{KMnO}_{4}$ used) enters through the presence of atmospheric oxygen, which error is greater in the presence of manganous sulphate or more especially titanium dioxide.

(5) By rapid titration in a stream of oxygen this error of No. 3 disappears, the oxygen acting on the oxalic acid tn give hydrogen peroxide, which requires a corresponding amount of permanganate.

(6) In the presence of much manganous sulphate, with oxalic acid of high concentration, especially in the presence of titanium dioxide, this hydrogen peroxide of No. 5 disappears, very rapidly if hot, and the error of No. 3 is then evident, as the compensating action of the hydrogen peroxide is not possible.

(7) Rapid titration at $50^{\circ}$ with $30 \mathrm{cc}$ of I : I stilphuric acid in $200 \mathrm{cc}$ of water gives results which agree with the iodine method of standardization.

Schroeder therefore recommends that the greater part of the permanganate be rapidly run into a strongly acidified solution of the oxalate and then the titration finished more slowly. Addition of manganous sulphate is not recommended.

The experimental data presented by Schroeder which are of importance to this discussion are those in his tables numbered $3,4,5,6$, IO, and II. These data, with very few exceptions, seem to warrant the following conclusions (not expressed by Schroeder, but drawn from his data): 
(a) High temperature tends to cause a smaller permanganate consumption. (Tables $3,4,5$, and 6.)

(b) High acidity tends to cause a high permanganate consumption. (Tables $3,4,5$, ro, and I r.)

(c) Slow titration (Io minutes) requires less permanganate than fast (I to $\mathrm{I} / 2$ minutes) titration.

(d) Presence of added manganous sulphate ( $\mathrm{I}$ to $5 \mathrm{~g}$ ) tends to cause less permanganate to be used, even with rapid titration. (Tables 5 and 6.)

(e) Titration in an air current required slightly more permanganate than in a current of carbon dioxide, when made either rapidly or slowly or in the presence of large or small amounts of acid.

It must be noted that in his experiments the stirring was very ineffective, since Schroeder often refers to his titration as "frequently whirled" (umgeschwenkt) and "whirled from time to time"; and no end-point corrections were made even when the titration was conducted rapidly, at low temperature, in the presence of large amounts of acid and manganous salt.

These conclusions as to the influence of conditions are confirmed, in general, by the data obtained in our own work, but it does not seem that the conclusions expressed by Schroeder (p. 634) necessarily follow from the data which he presents. In fact, from his own experimental results, we would infer, as stated by us in our conclusion (e) (second preceding paragraph), that the error due to atmospheric oxidation claimed by him (see (3) p. 634) does not exist. Although it is admitted that on long standing at high temperature oxalic acid in solution in the presence of much manganous sulphate is oxidized by the air, such combination of conditions is not met in the standardization of permanganate, and such oxidation does not take place to any such extent as claimed by Schroeder under the conditions which are properly employed. On the above basis we believe that Schroeder's conclusion (3) is not warranted, even by his own data.

If, as seems necessary, the explanation that loss of oxygen and not atmospheric oxidation is responsible for the variation of the 
permanganate values obtained under different conditions of titration, then the conclusions (5) and (6) expressed by Schroeder are not necessary for the explanation of the experimental data.

The fact that the use of the conditions chosen by Schroeder gave values which agreed well with those obtained by the iodine method of permanganate standardization (see (7) p. 634) would not prove that these conditions are correct, since no evidence is presented to show that the iodine standardization was carried out under conditions giving correct values. As a matter of fact, the iodine standardization is even more largely affected by conditions than is the oxalate method, and none of these influences have been systematically studied,

As has already been stated (p. 630), the experimental data obtained by the author do not indicate that any appreciable atmospheric oxidation of oxalic acid occurs during the course of a standardization. Moreover, Schroeder's data warrant the conclusion that when titrations are made in a stream of air, no less (and perhaps even more) permanganate is required than if made in a stream of carbon dioxide.

Therefore it appears certain that the oxidizing effect of the air during the permanganate-oxalate reaction will not have an appreciable influence upon the result obtained from such standardization.

\section{(e) INCOMPLETE OXIDATION OF THE OXALIC ACID}

In so far as our present knowledge goes there is no evidence to indicate any incompleteness in the oxidation of the oxalic acid. Since one of the products of the reaction, the carbon dioxide, is almost wholly removed from the sphere of action, there is little if any tendency to come to an equilibrium before the whole of the oxalate is oxidized. The reaction:

$$
\mathrm{Mn}^{\prime}\left(\text { or } \mathrm{MnO}_{4}\right)+\mathrm{H}_{2} \mathrm{C}_{2} \mathrm{O}_{4}=\mathrm{Mn}^{\prime} \cdot+\mathrm{H}_{2} \mathrm{O}+\mathrm{CO}_{2}
$$

can not be reversible, under the conditions of titration, and unless it be reversible unoxidized oxalic acid would hardly remain 
in the presence of an excess of permanganate. Moreover, if no free oxalic acid remains the complex $\mathrm{Mn}(\mathrm{OH})_{3} \cdot \mathrm{H}_{2} \mathrm{C}_{2} \mathrm{O}_{4}$ could not be stable, since it would be completely decomposed according to the reaction:

$$
\mathrm{Mn}(\mathrm{OH})_{3} \cdot \mathrm{xH}_{2} \mathrm{C}_{2} \mathrm{O}_{4}=\mathrm{Mn}(\mathrm{OH})_{3}+\mathrm{xH}_{2} \mathrm{C}_{2} \mathrm{O}_{4}
$$

Since the $\mathrm{H}_{2} \mathrm{C}_{2} \mathrm{O}_{4}$ formed by this last reaction is destroyed by the $\mathrm{KMnO}_{4}$ excess as fast as formed, the reaction would continue to the complete decomposition of the complex. The fact that the solutions at the end of a titration contain an excess of permanganate and do not lose oxidizing power, even after standing for half an hour or more at $90^{\circ}$, indicates that the oxidation of the oxalate must have been complete during the titration.

\section{(f) LOSS OF OXYGEN}

In a recent article Sarkar and Dutta ${ }^{14}$ claim that unlimited amounts of permanganate can be reduced by small amounts of organic material at high temperatures $\left(85\right.$ to $\left.90^{\circ}\right)$ and high acidity by the following cycle of reactions:

(a) ${ }_{5} \mathrm{H}_{2} \mathrm{C}_{2} \mathrm{O}_{4}+2 \mathrm{KMnO}_{4}+3 \mathrm{H}_{2} \mathrm{SO}_{4}=10 \mathrm{IO}_{2}+\mathrm{K}_{2} \mathrm{SO}_{4}+2 \mathrm{MnSO}_{4}+8 \mathrm{H}_{2} \mathrm{O}$

(b) ${ }_{3} \mathrm{MnSO}_{4}+2 \mathrm{KMnO}_{4}+2 \mathrm{H}_{2} \mathrm{O}=5 \mathrm{MnO}_{2}+\mathrm{K}_{2} \mathrm{SO}_{4}+2 \mathrm{H}_{2} \mathrm{SO}_{4}$

(c) $2 \mathrm{MnO}_{2}+2 \mathrm{H}_{2} \mathrm{SO}_{4}=2 \mathrm{MnSO}_{4}+2 \mathrm{H}_{2} \mathrm{O}+\mathrm{O}_{2}$

(d) $3 \mathrm{MnSO}_{4}+2 \mathrm{KMnO}_{4}+2 \mathrm{H}_{2} \mathrm{O}=5 \mathrm{MnO}_{2}+\mathrm{K}_{2} \mathrm{SO}_{4}+2 \mathrm{H}_{2} \mathrm{SO}_{4}$

Similarly other authors have claimed that oxygen is evolved from the interaction of sulphuric and permanganic acids. ${ }^{15}$

In reply to Sarkar and Dutta's claim Skrabal ${ }^{16}$ has proposed the following scheme as explaining the evolution of oxygen when

14 Zs. anorg. Chem., 67, pp. 225-233; x910.

15 Hirtz and Meyer: Ber., 29, pp. 2828-2830; r896. Gooch and Danner: Am. J. Sci., [3] 4t, pp. 30I-3Io; 1892. Jones: J. Chem. Soc., 33, p. 95; 1878.

${ }^{16}$ Zs. anorg. Chem., 68, pp. 48-51; 1910. 
permanganate and oxalic acid react. (Compare with this author's scheme for the normal reaction given on p. 6I 5 ):

I. Incubation period:

II. Induction period:

$$
\mathrm{Mn}^{\mathrm{VII}} \rightarrow \mathrm{Mn}^{\mathrm{II}}+\mathrm{O}_{2}
$$

$$
\mathrm{Mn}^{\mathrm{VII}}+\mathrm{Mn}^{\mathrm{II}} \rightarrow \mathrm{Mn} \text { III }\left\{\begin{array}{l}
\rightarrow \mathrm{Mn}^{\mathrm{II}}+\mathrm{Mn}^{\mathrm{IV}} \\
\text { or } \\
\rightarrow \mathrm{Mn}^{\mathrm{II}}+\mathrm{O}_{2}
\end{array}\right.
$$

III. End period:

$$
\mathrm{Mn}^{\mathrm{IV}} \rightarrow \mathrm{Mn}^{\mathrm{II}}+\mathrm{O}_{2}
$$

Whether one wishes to accept this last scheme or that of Sarkar and Dutta, or even some entirely different explanation, the fact remains that oxygen may be evolved during the course of these reactions when they take place under certain conditions. Such oxygen loss would be expected under either of the following conditions, viz, an increased concentration of acid or an increased concentration of $\mathrm{HMnO}_{4}$ or $\mathrm{MnO}_{2}$ (and possibly also of $\mathrm{Mn}_{2} \mathrm{O}_{3}$ ) in the solution. The first of these conditions is produced by direct increase in amount of acid added, and the result has been shown to be an increased permanganate consumption. (See Tables III and IV.) The presence of $\mathrm{HMnO}_{4}, \mathrm{MnO}_{2}$, and perhaps $\mathrm{Mn}_{2} \mathrm{O}_{3}$, one or all, is caused by any one of the following influences: Low temperature, which decreases the rate of their reduction to the manganous condition. Large bulk of solution, which reduces the oxalate concentration, and therefore the rate of their reduction to manganous condition. Rapid addition of permanganate (especially at the start or just before the end point) or insufficient stirring, both of which allow the unreduced or partially reduced manganese to accumulate throughout or in parts of the solution.

Each of these conditions has been shown to cause an increase in the permanganate used for the titration. On the other hand, addition of manganous sulphate, which increases the rapidity of the reduction of the manganese, causes a decreased consumption of permanganate. (See Table VIII.)

To briefly summarize these points: The loss of small amounts of oxygen, which certainly does occur under some conditions, 
would account for the effect noted in all of the experiments described where change of temperature, of acidity, of volume, of rate of addition of the permanganate, of rate of stirring, or the addition of manganous sulphate has an appreciable influence upon the result of the standardization. Since with proper precautions these variations can be reduced, indeed almost eliminated, over considerable ranges of temperature, acidity, and volume of solution, there is good reason to believe that the loss of oxygen is almost, if not wholly, prevented. In this connection, it must again be emphasized that vigorous stirring throughout the titration, and slow addition of the permanganate at the beginning and at the end, are essential if correct results are to be had.

(g) INCOMPLETE REDUCTION OF THE PERMANGANATE

It has been shown in the discussion of the end-point corrections (pp. 620-62 I) that in addition to permanganate there is often manganic $\left(\mathrm{Mn}^{\cdots \cdot}\right)$ or tetravalent manganese $\left(\mathrm{Mn}^{\cdots \cdot \cdot)}\right.$ ) salt present at the end point. However, the error caused by their presence is corrected by the end point "blank" described above, and therefore need not be considered as influencing the results already given. In the ordinary titration, such error would be serious only if improper conditions of titration were chosen. The conditions recommended below entirely eliminate this source of error.

(h) IMPURITIES IN THE OXALATE

The question of purity of the soidum oxalate, water, and acid, used in the titration, must, of course, be considered; but there is no need for appreciable error to arise due to this source if the simple tests referred to above under "reagents used" are applied. As especially affecting the present discussion this source of error has been eliminated even beyond the accuracy of the tests for purity of the oxalate, since only comparative values were employed.

(i) ABNORMAL OXIDATION PRODUCTS

Several abnormal products of the oxidation can be imagined, for example, carbon monoxide, hydrogen, hydrogen peroxide, and oxides of carbon higher than carbon dioxide. It is not at all $73764^{\circ}-13-3$ 
probable that either hydrogen or carbon monoxide should result from such a reaction as that under consideration, since the former would be liberated in a nascent state very easily oxidized and the latter could be formed only by a decomposition of the oxalate molecule in a way never observed except under the action of a strong dehydrating agent, e. g., concentrated sulphuric acid.

The possibility of the formation of hydrogen peroxide or higher carbon oxides has been discussed by Schroeder. ${ }^{17}$ This could lead to error under only the first of the following two conditions, viz, that they subsequently decomposed, setting free oxygen, or that they remained intact at the end point. The former condition has already been discussed (p. 637); the latter possibility, that they remain unacted upon to the end of the titration, is both improbable and immaterial, since, when the end-point correction is employed, the excess of oxygen which they might contain would undoubtedly be corrected for by the "blank" as determined with potassium iodide.

\section{SUMMARY AND CONCLUSIONS}

As is indicated in the discussion immediately preceding, there appear to be only two sources of variation from the normal course of the reaction which are at all probable, viz, loss of oxygen from the solution or oxidation of part of the oxalic acid by atmospheric action. Although either of these theories explains a large part of the experimental facts, only the former can be held in the light of the experiments of Table VII and the other facts discussed in connection with this table.

Therefore, if the main source of error is due to oxygen losses, the higher values obtained in the various series are more nearly correct. This conclusion has been accepted as a working basis for the recommendations regarding choice of conditions for titration. Indeed such choice can not be far in error, since the greatest discrepancies noted under wide ranges of conditions is not over 0.2 per cent (not including errors due to long standing, inefficient stirring, and excessively rapid permanganate addition just at the end point). 


\section{METHOD RECOMMENDED FOR USE}

Although it can be seen that under quite varied conditions of standardization, the values obtained for the permanganate will vary less than I part in Iooo, it seems desirable to fix more definitely the conditions of titration, both in order to make the results obtained slightly more precise and also to insure the use of those conditions under which the difficulty of proper operation is a minimum. For this purpose the following detailed method of operation is recommended:

In a 400-cc beaker, dissolve $0.25^{-0.3} \mathrm{~g}$ of sodium oxalate in 200 to $250 \mathrm{cc}$ of hot water $\left(80\right.$ to $\left.90^{\circ}\right)$ and add ro cc of (I:I) sulphuric acid. Titrate at once with $\mathrm{N} /{ }_{10} \mathrm{KMnO}_{4}$ solution, stirring the liquid vigorously and continuously. The permanganate must not be added more rapidly than Io to $5 \mathrm{cc}$ per minute and the last $1 / 2$ to I cc must be added dropwise with particular care to allow each drop to be fully decolorized before the next is introduced. The excess of permanganate used to cause an end-point color must be estimated by matching the color in another beaker containing the same bulk of acid and hot water. The solution should not be below $60^{\circ}$ by the time the end point is reached; more rapid cooling may be prevented by allowing the beaker to stand on a small asbestos-covered hot plate during the titration. The use of a small thermometer as stirring rod is most convenient in these titrations, as the variation of temperature is then easily observed.

\section{ACCURACY AIND PRECISION ATTAINABLE}

The agreement of duplicates in the numerous tables given above shows the precision which can be expected in the use of sodium oxalate when the conditions or titration are regulated. It appears that agreement of duplicates to I part in 2000 should be regularly obtained if weight burettes are used. Failure to obtain this precision should be at once taken to mean that some condition has not been regulated with sufficient care.

Although the absolute accuracy of the values obtained under different conditions has not yet been studied, it seems probable 
that if the method recommended is followed the error will not exceed 0.1 per cent and probably will be less than 0.05 per cent. It is hoped to undertake a comparison of this method with other oxidimetric standards, particularly iron, silver, and iodine, in order to check its value. However, such work involves one uncertainty which renders the best results which could be obtained probably no more conclusive than those now at hand. The difficulty is that of end points, for in each case mentioned the uncertainty in the blank correction required for an end point is about of the same order as that of the uncertainty in the oxalate values, namely, o.I per cent (usually equivalent to $0.05 \mathrm{cc}$ of $\mathrm{N} / \mathrm{ro} \mathrm{KMnO}_{4}$ ). We therefore, at the present time, would assume no greater absolute accuracy for the values obtainable than one-tenth of I per cent.

WASHINGTON, June I, I9I2. 